\title{
Invasive Haemophilus influenzae Type b (Hib) Infections in Children in the Pediatric Department of the University Hospital Gabriel Touré (UH-GT)
}

\author{
B. Maiga*, A. A. Diakité, K. Sacko, M. Sylla, M. Maiga, M. E. Cissé, A. Dembélé, F. Traoré, D. Konaté, \\ F. L. Diakité, L. Sidibé, A. K. Doumbia, O. Coulibaly, P. Togo, A. Touré, K. Traoré, L. Maiga, \\ A. Ibrahim, H. Diall, A. Doumbia, H. Konare, S. Sagara, M. Niakaté, A. Cissouma
}

Pediatric Departement, University Hospital Gabriel Touré, Bamako, Mali

Email: ^belcosmaiga@yahoo.fr

How to cite this paper: Maiga, B., Diakité, A.A., Sacko, K., Sylla, M., Maiga, M., Cissé, M.E., Dembélé, A., Traoré, F., Konaté, D., Diakité, F.L., Sidibé, L., Doumbia, A.K., Coulibaly, O., Togo, P., Touré, A., Traoré, K., Maiga, L., Ibrahim, A., Diall, H., Doumbia, A., Konare, H., Sagara, S., Niakaté, M. and Cissouma, A. (2021) Invasive Haemophilus influenzae Type b (Hib) Infections in Children in the Pediatric Department of the University Hospital Gabriel Touré (UH-GT). Open Journal of Pediatrics, 11, 100-107. https://doi.org/10.4236/ojped.2021.111009

Received: January 3, 2021

Accepted: March 7, 2021

Published: March 10, 2021

Copyright $\odot 2021$ by author(s) and Scientific Research Publishing Inc. This work is licensed under the Creative Commons Attribution International License (CC BY 4.0).

http://creativecommons.org/licenses/by/4.0/

(c) (i) Open Access

\begin{abstract}
Introduction: According to Mali's National Immunization Center, the Haemophilus influenzae b (Hib) vaccine coverage rate was $90 \%$ in 2015. Our work aimed to study invasive bacterial infections due to Haemophilus influenzae type $\mathrm{b}$ in children aged 0 - 15 years hospitalized in the pediatrics department of the UH-GT. Method: We carried out a retrospective descriptive study from January 2017 to December 2018 (i.e. 2 years) among children aged 0 15 years and hospitalized for Haemophilus influenzae type b infection confirmed by culture (blood culture, Cerebro-spinal Fluid, and pleural and skin fluid). Results: Thirty-three cases of Hib infections were collected giving a frequency of $0.2 \%$ and the age group 3 months to 3 years was the most affected (72.73\%). Children who received no vaccine accounted for $21.21 \%$. The Cerebro-spinal Fluid culture and other samples (pleural and skin) identified the bacterium in $100 \%$ of cases, against $72.72 \%$ in the blood culture Meningitis was the most frequent pathology $(78.79 \%)$ and the lethality was high $(21.21 \%)$. Conclusion: Despite the introduction of the Hib vaccine in the routine immunization program in Mali, Hib infections remain with a high lethality linked to meningitis.
\end{abstract}

\section{Keywords}

Invasive Bacterial Infections, Haemophilus influenzae b, Children, Pediatrics 


\section{Introduction}

According to the World Health Organization (WHO) estimates [1], Hib still causes at least 3 millions cases of serious illness and nearly 386,000 deaths yearly, the vast majority of them in developing countries and therefore with low immunization coverage. WHO recommends the inclusion of Hib vaccination in all routine infant immunization programs with a 3-dose primary schedule with or without a booster dose or 2 primary doses plus a booster dose [2]. At the end of 2007, more than 122 countries have introduced the vaccine into their childhood immunization programs according to WHO [2]. The impact of vaccination on the incidence of invasive Hib infections was a dramatic decrease of more than 95\% in the first years after its implementation [3]. In fact, invasive Hib pathologies have practically disappeared in many industrialized countries and their incidence has dropped dramatically in countries where vaccination coverage is satisfactory. It is estimated that $92 \%$ of children in industrialized countries are immunized against $\mathrm{Hib}$, while the immunization rate is estimated near $42 \%$ in developing countries and $8 \%$ in least developed countries mainly in sub-Saharan Africa [1] [4].

In Mali, hospital surveillance of invasive bacterial diseases carried out by the Center for the Development of Vaccines (CVD-Mali) since 2002 has revealed a high incidence of invasive disease due to Haemophilus influenzae type b [5]. The results of this surveillance led to the introduction of the Hib conjugate vaccine into the Expanded Immunization Program in July 2005.

After the introduction of vaccination annual confirmed Hib hospitalizations in infants from 0 to 11 months decreased from $175 / 100,000$ to $44 / 100,000$ and in infants 6 - 7 months from 377/100,000 to 69/100,000, i.e. a decrease of $82 \%$ [6]. According to the National Immunization Center of Mali, the Hib vaccination coverage rate was $90 \%$ in 2015 [7]. Ten years after the introduction of the Hib vaccine, we thought it appropriate to do a study on invasive bacterial Hib infections in pediatric environment.

\section{Methodology}

Our study was carried out in the pediatrics department of the UH-GT, a tertiary hospital located in the center of the city of Bamako.

This was a retrospective and descriptive study involving children aged from 0 to 180 months, admitted for a confirmed bacterial infection by Hib between January 1, 2017 to December 31, 2018 (i.e. 24 months).

Included were any patient with confirmed bacterial Hib infection either in cerebro spinal fluid (CSF), blood culture, or any other sample. This is a comprehensive sample of all children 0 to 180 months of age hospitalized during the study period for confirmed Haemophilus influenzae b infection. We developed a survey formulary that allowed us to collect data from hospitalization records, the inclusion register of participants in the pediatric unit of the Center for Vaccin Development (CVD) and the laboratory results register. 
The variables studied were: epidemiological, clinical, biological, therapeutic and evolutionary characteristics.

Data analysis and processing was performed on SPSS software version 20.0. Chi-square and Fisher statistical tests were used. Data confidentiality was respected.

\section{Results}

\subsection{Sociodemographic Characteristics}

During the study period 33 cases of confirmed invasive infections with Haemophilus influenzae type $\mathrm{b}$ were identified out of a total hospitalization of 16228 , giving a frequency of $0.2 \%$.

The 3 - 36 months age group was the most represented (72.73\%) with an average age of 6 months and extremes of 2 to 156 months. The Boys:Girls ratio was 1.75. More than half of our sample (55.55\%) resided in Bamako. The peak of admission was in December. A proportion of $54.55 \%$ was correctly immunized and $21.21 \%$ have no vaccine according to the vaccination record

\subsection{Clinical and Biological Characteristics}

Febrile convulsion was the most frequent reason for consultation with $27.27 \%$ followed by respiratory distress with $21.21 \%$ and meningeal signs (18.18\%). Fever was observed in the majority of patients $(72.72 \%)$, and the mean temperature at admission was $38.4^{\circ} \mathrm{C}$. Malnutrition was associated with $\mathrm{Hib}$ infection in $33.33 \%$ of cases, with HIV infection in $6 \%$ of cases. Bacterial meningitis was the most common diagnosis $(78.79 \%)$, followed by sepsis $(9.09 \%)$ and pneumonia (6.06\%).

The rate of isolation of the bacterium in the CSF, pleural effusion and cutaneous lesions was $100 \%$, but it was $72.72 \%$ on the blood culture.

\subsection{Evolution}

The average length of hospital stay was 11 days with extremes of 1 to 31 days. The case mortality was $21.21 \%$.

\section{Discussion}

During the study period 33 cases of confirmed invasive infections with Haemophilus influenzae type b were identified out of a total hospitalization of 16,228 giving a frequency of $0.2 \%$. Sow et al. [6] in Mali reported a decrease of incidence and hospitalization due to Hib after the introduction of the pentavalent vaccine in July 2005 with hospitalizations going from $377 / 10^{5}$ to $69 / 10^{5}$. In Egypt, the number of confirmed cases of Hib meningitis is 23/100,000 among children under 5 years [8]. Also David W et al. [9], reported that the Haemophilus influenzae type $\mathrm{b}$ conjugate vaccine reduced the annual number of cases of $H$. influenzae type $\mathrm{b}$ meningitis in children. Although the prevalence of Haemophilus influenzae infection significantly decreased, $21.21 \%$ of the children did not re- 
ceive any vaccine according to the vaccination schedule. In 2007, Haemophilus influenzae B vaccine coverage was $96.7 \%$ in Burkina Faso [10], 68\% in the Gambia [11]. This situation urges health authorities to strenghten their efforts to immunize children who still miss the immunization program (Table 1).

Classically the authors divide the ages of children into three groups: less than one year old, one to five years old and more than five years old. We preferred the distribution in less than three months, three months to three years, three years to five years and more than five years. This subdivision is based on the evolution of anti-Hib antibody titers in children (Tables 2-5).

Table 1. Sociodemographic characters in the sample of 33 patients with Haemophilus influenzae type b infection.

\begin{tabular}{ccc}
\hline Sociodemographic characters & Number $(\mathbf{n}=33)$ & $\%$ \\
\hline Age in months & 5 & 15.15 \\
$0-3$ & 24 & 72.73 \\
$3-36$ & 2 & 6.06 \\
$36-59$ & 2 & 6.06 \\
60 and more & & \\
Sex & 21 & 36 \\
Boys & 12 & 64 \\
Girls & & \\
Residence & 18 & 54.55 \\
Bamako & 15 & 45.45 \\
Outside Bamako & & \\
Immunization according PEV & $\mathbf{1 8}$ & $\mathbf{5 4 . 5 5}$ \\
Up to date & 8 & 24.24 \\
Not up to date & 7 & 21.21 \\
No immunization &
\end{tabular}

*Programme élargi de vaccination: extendend immunization program.

Table 2. Distribution of the patients according to consultation reason in the sample of 33 patients with Haemophilus influenzae type b infection.

\begin{tabular}{ccc}
\hline Reason for consultation & Number & $\%$ \\
\hline Convulsion with fever & 9 & 27.27 \\
Respiratory distress & 7 & 21.21 \\
Meningeal signs & 6 & 18.18 \\
Fever & 5 & 15.15 \\
Skin tumor & 2 & 6.06 \\
Acute severe Malnutrition & 2 & 6.06 \\
Others & 2 & 6.06 \\
Total & 33 & 100 \\
\hline
\end{tabular}

Others: 1 case of palor and 1 case of anuria. 
Table 3. Patients distribution based on labor assessments in the sample of 33 patients with Haemophilus influenzae type b infection.

\begin{tabular}{ccc}
\hline \multirow{2}{*}{ Labor test } & \multicolumn{2}{c}{ Results in \% } \\
\cline { 2 - 3 } & Positive & Negative \\
\hline Cultur of meningeal fluid & 100 & 0 \\
Other testz (pleural and skin) & 100 & 0 \\
Blood culture & 72.72 & 27.28 \\
\hline
\end{tabular}

Table 4. Patients distribution according to diagnosis in the sample of 33 patients with Haemophilus influenzae type $\mathrm{b}$ infection.

\begin{tabular}{ccc}
\hline Diagnosis & Number & $\%$ \\
\hline Meningitis & 26 & $\mathbf{7 8 . 7 9}$ \\
Sepsis & 3 & 9.09 \\
Pneumonia & 2 & 6.06 \\
Pleural effusion & 1 & 3.03 \\
Myositis with abcess & 1 & 3.03 \\
Total & 33 & 100 \\
\hline
\end{tabular}

Table 5. Distribution of evolution in the sample of 33 patients with Haemophilus influenzae type $\mathrm{b}$ infection.

\begin{tabular}{ccc}
\hline Evolution & Number & $\%$ \\
\hline Full recovery & 19 & 57.57 \\
Death & 7 & 21.21 \\
Discharge against medical advise & 7 & 21.21 \\
Total & 33 & 100 \\
\hline
\end{tabular}

The 3 - 36 montha age group was the most represented with $72.73 \%$. This age group was largely found by CISSE in Dakar with 92\% [12]. These results confirm that Hib meningitis is typically a disease of young children. In addition, they establish the correlation between anti-Hib antibody titers and the frequency of Hib infections in children. Indeed, before three months the child is protected by maternal antibodies. Between three months and three years of age, the child has lost maternal antibodies and his immune system does not produce enough antibodies. Therefore, they are more exposed to infections including Hib. Between the ages of three and five, a child is still protected because his immune system hasprogressive implementation. After five years, antibody titers are at their maximum and its protection is complete in the absence of any immune deficiency [13].

Hib is endemic with periods of recrudescence without significant impact of temperature and rainfall. Indeed, Sow et al. [6], had already reported the nonseasonality of Haemophilus influenzae b infection in Mali. On the other hand, Diawara A. et al. reported that the distribution of the disease was higher during 
the dry season (November-April) (51.0\%) than during the rainy season (MayOctober) (49.0\%) [14].

Camara B. et al. [15] observed that Hib meningitis is encountered throughout the year with a peak occurring between January and March, that is, during the dry and cold season.

In sub sahara Africa, the cold season is very favorable to the expansion of EarNose-Larynx and respiratory infections which are the beds of bacterial meningitis. In addition, the chronic carriage of Hib in the nasopharynx of children would explain the onset of the disease throughout the year.

The peak at the start of the dry season in the tropics could be attributed to the sudden change in physiological mechanisms of adaptation to the cold.

Bacterial meningitis was the most common diagnosis (78.79\%), followed by sepsis $(9.09 \%)$, and pneumonia (6.06\%). The predominance of meningeal localization of Hib has been reported by several authors [8] [16] [17].

Despite the administration of antibiotics in our health structures due to insufficient laboratory tests, all cases of meningitis were diagnosed by culture of the CSF. Pederson et al. [18] in Denmark confirm our result with 100\% of cases of meningitis confirmed by CSF culture.

We recorded a lethality of $21.21 \%$ less than that reported by Cissé et al. in Senegal [12], Tall F et al. in Burkina Faso [19] with 32.7\% and 26\% respectively.

Our high lethality could be explained by: the delay in diagnosis, the weakness of the technical equipement (lack of intensive care units) and co-morbidities (malnutrition in $33.33 \%$ of cases, HIV infection in $6 \%$ of cases).

\section{Conflicts of Interest}

The authors declare no conflicts of interest regarding the publication of this paper.

\section{References}

[1] Bärnighausen, T., Bloom, D.E., Canning, D., Friedman, A., Levine, O.S., O’Brien, J., Privor-Dumm, L. and Walker, D. (2011) Rethinking the Benefits and Costs of Childhood Vaccination: The Example of the Haemophilus influenzae Type B Vaccine. Vaccine, 29, 2371-2380. https://doi.org/10.1016/j.vaccine.2010.11.090

[2] World Health Organization (2017) Vaccination, Vaccins et Produits Biologiques. https://www.who.int/immunization/policy/Immunization routine

[3] Booy, R., Hodgson, S., Carpenter, L., Mayon-White, R.T., Slack, M.P., Macfarlane, J.A., et al. (1994) Efficacy of Haemophilus influenzae Type B Conjugate Vaccine PRP-T. Lancet, 344, 362-366. https://doi.org/10.1016/S0140-6736(94)91400-1

[4] Peltola, H. (2000) Worldwide Haemophilus influenzae Type B Disease at the beginning of the 21st Century: Global Analysis of the Disease Burden 25 Years after the Use of the Polysaccharide Vaccine and a Decade after the Advent of Conjugates. Clinical Microbiology Reviews, 13, 302-317. https://doi.org/10.1128/CMR.13.2.302

[5] Sow, S.O., Diallo, S., Campbell, J.D., Tapia, M.D., Keita, T., Keita, M.M., et al. (2005) Burden of Invasive Disease Caused by Haemophilus influenzae Type B in 
Bamako, Mali: Impetus for Routine Infant Immunization with Conjugate Vaccine. The Pediatric Infectious Disease Journal, 24, 533-537. https://doi.org/10.1097/01.inf.0000164768.28135.0d

[6] Sow, S.O., Tapia, M.D., Diallo, S., Keita, M.M., Sylla, M., Onwuchekwa, U., et al. (2009) Haemophilus influenza Type B Conjugate Vaccine Introduction in Mali: Impact on Disease Burden and Serologic Correlate of Protection. American Journal of Tropical Medicine and Hygiene, 80, 1033-1038.

https://doi.org/10.4269/ajtmh.2009.80.1033

[7] Programme Elargide Vaccination(PEV) (2016) du Mali MSHP MARS 2016. Equipe. Section Immunisation/DNS.

http://www.sante.gov.ml/index.php/actualites/communiques/item/download/313 7 6379ed9011d9fe8c3b7f2d8baa8c754

[8] Zareia, A.E., Linjawic, M.H. and Redwana, E.M. (2016) Circulating Anti-Haemophilus influenzae Type B, Antibodies Contributing to Direct and Herd Immunity. Wulfenia Journal, 23, 22-55.

[9] McCormick, D.W. and Molyneux, E.M. (2011) Bacterial Meningitis and Haemophilus influenzae Type b Conjugate Vaccine, Malawi. Emerging Infectious Diseases, 17, 668-690. https://dx.doi.org/10.3201/eid1704.101045

[10] Kabore, N.F., Poda, G.A., Barro, M., Cessouma, R., Hema, A., Ouedraogo, A.S., Sawadogo, A.B. and Nacro, B. (2012) Impact de la vaccination sur les admissions pour méningites à Haemophilus influenzae b de 2004 à 2008, à Bobo Dioulasso (Burkina Faso). Médecine et Santé Tropicales, 22, 425-429. https://www.jle.com/10.1684/mst.2012.0122

[11] Renner, L.A., Newman, M.J., Ahadzie, L., Antwi-Agyei, K.O. and Eshetu, M. (2007) Introduction of Haemophilus influenzae Type B Conjugate Vaccine into Routine Immunization in Ghana and Its Impact on Bacterial Meningitis in Children Younger than Five Years. The Pediatric Infectious Disease Journal, 26, 356-358.

https://doi.org/10.1097/01.inf.0000258693.19247.8e

[12] Cisse, M.F, Breugelmans,G.J., Bâ, M., Diop, M.B., Faye, P.C., Mhlanga, B., et al. (2010) The Elimination of Haemophilus influenzae Type B Meningitis Following Conjugate Vaccine Introduction in Senegal. Vaccine Impact in Senegal. The Pediatric Infectious Disease Journal, 29, 499-503. https://doi.org/10.1097/INF.0b013e3181ccb0a0

[13] Aujard, Y. (1999) Méningites purulentes du nouveau-né, du nourrisson, et de l'enfant. In Manuel du. Généraliste. Encyclo Méd chir, AKOS Encyclopédie Pratique de Pédiatrie, 8-0770, Elsevier, Paris, 5 p.

[14] Diawara, A., Sangho, H., Sissoko, M., Bougoudogo, F. and Doumbo, O. (2008) Haemophilus influenzae Type B parmi les méningites bactériennes à Bamako (20022004). Mali Medical, 23, 43-46.

[15] Camara, B., Faye, F.M., Diouf, S., Gueye-Diagne, N.-R., Diagne, I., Cissé, M.-F., et al. (2007) Méningite pédiatrique à Haemophilus influenzae b à Dakar. Médecine et Maladies Infectieuses, 37, 753-757. https://doi.org/10.1016/j.medmal.2007.03.002

[16] Pablo, C.R., Alejandro, D.F., Jorge, C.A. and Marcela, L.H. (2006) Infections Invasives dues àHaemophilus influenzae detype $\mathrm{b}$ aprèsl'incorporation du vaccin conjugué dans le programme élargi de vaccination au Chili. Rev Chil Infect, 23, 50-54.

[17] Scheifele, D., Halperin, S., Law, B. and King, A. (2005) Invasive Haemophilus influenzae Type B Infections in Vaccinated and Unvaccinated Children in Canada, 2001-2003. Canadian Medical Association Journal, 172, 53-56.

https://doi.org/10.1503/cmaj.1031861 
[18] Pedersen, T.I., Howitz, M. and Ostergaard, C. (2010) Clinical Characteristics of Haemophilus influenzae Meningitis in Denmark in the Post-Vaccination Era. Clinical Microbiology and Infection, 16, 439-446. https://doi.org/10.1111/j.1469-0691.2009.02841.x

[19] Tall, F., Elola, A., Sanou, I., et al. (2006) Méningite à Haemophilus et immunité naturelle anti-Haemophilus influenzae type b (Hib) chez les enfants au Burkina Faso. The Pediatric Infectious Disease Journal, 25, 415-419. 